\title{
VARGAS LLOSA O EL VÉRTIGO DE LA FORMA
}

\section{J. Ernesto Ayala-Dip}

Leyendo, hace ya unos años, un libro de teoría literaria, Teoría de la novela: Antología de textos del siglo XX, editado por Enric Sullà (Crítica, 1996), J. E. Ayala-Dip encontró un texto de Vargas Llosa titulado "El arte de mentir" (Revista de la Universidad de México, 1984). Le llamó la atención que el nombre del novelista ya consagrado, estuviese al lado de otros no menos consagrados narratólogos, entre los cuales no faltaban G. Genette, W. C. Booth, U. Eco, R. Barthes, entre otros. Ello, entonces, le hizo pensar sobre un aspecto específico de la obra de Vargas Llosa: su pasión por la escritura, no sólo como praxis cotidiana sino también como núcleo de reflexión metaliteraria. Este artículo trata de ello. De esa dedicación de Vargas Llosa al trabajo de otros escritores (sus afinidades electivas) y de su propio discurso teórico sobre el hecho literario como proceso autónomo de ficcionalización.

J. ERnesto Ayala-Dip (Buenos Aires, 1945). Crítico de literatura española y latinoamericana, escribe en el suplemento de libros (hoy Babelia) del diario El País y en la sección de opinión (en la edición nacional y El País de Cataluña) y cultura. También colabora semanalmente, desde hace veinte años, en el suplemento "Territorios de la Cultura" del diario El Correo de Bilbao. Autor de ensayos temáticos (sobre Javier Tomeo, Enrique Vila-Matas, Walter Benjamin y Juan Marsé, etc.), varios artículos suyos han sido recogidos en historias de la literatura española.Ayala_dip@yahoo.es. 


\section{La pasión de escribir}

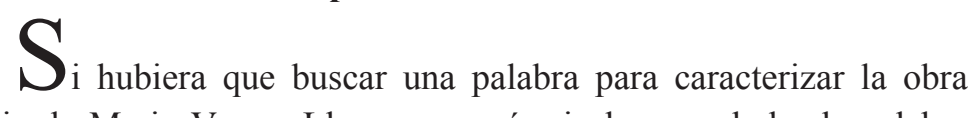
literaria de Mario Vargas Llosa, esa sería sin lugar a dudas la palabra pasión. Ella nos permite entender que ese sentimiento no sólo afecta a su empeño como autor, como creador, sino al también no menos crucial en su obra (y debería serlo en la obra de todo escritor aunque no siempre se haga notar), empeño como lector. No ha transcurrido un año, cuando todavía resuena en los oídos incrédulos de muchos lectores y admiradores suyos, su meridiana defensa de Milenium, la trilogía que se puso tan masivamente e inesperadamente de moda del escritor sueco Stieg Larsson (El País, septiembre de 2010). Los argumentos esgrimidos en dicho artículo no tienen nada que ver con el fogonazo de la repentina admiración o la fascinación indescriptible del que sólo sabe inclinarse sin más ante la obra incontestable. Tal defensa hacía hincapié fundamental en el placer que la lectura de la trilogía deparaba al premio Nobel. Releyendo hoy esas páginas, a un año de su publicación, extraemos de ellas el papel de la fruición en el arte de la lectura. Claro que Vargas Llosa (MVLl) da suficientes razones para ser convincente en su defensa. Y esas razones, por supuesto, que son de gran utilidad para entender la forma y el fondo de la obra de Larsson. Y además de útiles para entender esa trilogía en su contexto literario y extraliterario, nos ayudan a comprender una inteligencia (la del autor de la defensa) abierta y tolerante. (Digamos, para que el lector se haga una idea de cómo debió de caer el artículo del autor peruano en no pocas mentes cerriles, que en España se abrió prácticamente todo un debate alrededor de la publicación de la trilogía del autor escandinavo: sobre la pertenencia de esta obra al concierto de las obras merecedoras de respeto literario y lector, y ya no digamos de respeto por parte de una personalidad de la talla internacional de MVL1). Dicha defensa, a día de hoy, no obstante pone sobre el tapete la cuestión que a mí ahora me interesa destacar en esta breve introducción: la pasión de MVLl como lector y cómo esa pasión como lector redunda, además de determinar su voracidad temática, en la obra del escritor peruano. Esa pasión muchas veces bien la podríamos asociar a la desmesura que el mismo autor encuentra en otros autores: desmesura que lo admira y fascina y le hace reflexionar desde ella misma sobre los grandes problemas narrativos que afectan a ciertos 
maestros de la literatura universal. No es precisamente la desmesura un concepto que lo retraiga de aquella admiración, todo lo contrario. La desmesura y su pasión por ella, además de la pasión por la literatura son los ingredientes que MVL1 halla en Victor Hugo, sobre todo en el Hugo de Los miserables. Observemos sino el título del ensayo con el que se acerca a esta novela: La tentación de lo imposible (2004). La desmesura y la pasión, en su doble vertiente de escritor y lector, confluyen en este ensayo, sin que se explicite, como llaves hermenéuticas de Los miserables, pero también como llaves no menos hermenéuticas del propio premio Nobel. Qué puede acercarnos a lo imposible sino la pasión por la desmesura o la desmesura de la pasión. Creo que a MVLl le atrajo de Larsson, precisamente esa idea cercana a lo titánico, la fuerza desmesurada de lo mesiánico, la pasión ingobernable por la verdad. Si leemos atentamente, muy atentamente toda la obra de MVL1 desde sus primeros cuentos hasta su reciente novela, El sueño del celta (2010), sobre el papel genocida de Leopoldo II de Bélgica en África, será muy difícil que no se nos contagie todo el sentido de la desmesura totalizante y la pasión que ello exige.

De la misma manera que Vargas Llosa nos dice en su ensayo sobre Los miserables que el autor francés debe ser uno de los autores más estudiados del mundo, con multitud de ensayos, opúsculos, introducciones, prólogos, biografías, etc., también podríamos decir algo parecido de él mismo. La variedad de temas que ha abordado, la variedad de registros narrativos, de géneros (cuento, novela, teatro, ensayo, artículos periodísticos sobre política, literatura o vida cotidiana), parecen a veces agotar las posibilidades de la literatura, en todas sus variantes ficcionales y discursivas. Desde la ficción, Vargas Llosa defiende la ficción. Desde de ella, defiende la libertad del hombre. Y desde el ensayo, MVLl defiende y define la maquinaria narrativa de otros escritores que fueron mentores suyos, ya sea en el arte de la construcción artística como en el arte del aliento épico. La orgía perpetua: Flaubert y Madame Bovary (1975) y Carta de batalla por Tirant lo Blanc (1993) son muestras cabales de esa necesidad suya de apuntalar el hecho novelesco en sólidos cimientos. Precisamente en esta dirección me gustaría que ahondara mi colaboración. En la convicción que tiene el maestro peruano en el mecanismo persuasivo que todo edificio novelesco lleva en su interior. 


\section{La novela por dentro}

"Escribir, en la realidad ficticia, es siempre engañar; la escritura es el reino de la fantasía", dice MVL1 en La orgía perpetua. El escritor tiene como axioma la frontera entre lo que él llama la realidad real y la realidad ficticia. No deja de ser sorprendente que quien trabaja tanto en el territorio de la realidad, haya teorizado tanto respecto de los mecanismos de encantamiento narrativo. Desde sus primeras novelas, $L a$ ciudad y los perros (1962) y La casa verde (1966), nuestro autor ha interiorizado el poder de ilusionismo de la novela. Supo que todo escritor verdadero tiene una sala de máquinas desde donde urde sus artefactos de ilusionismo. Con ello se logra dos cosas: esquivar el burdo concepto de la novela como reflejo de la realidad y a la vez obtener una representación autónoma y palpitante de la misma. El autor de Conversación en La Catedral (1969) no ignora la vinculación que existe entre realidad y ficción, una vinculación ambigua: "Ésta es la curiosa ambigüedad de la ficción: aspirar a la autonomía sabiendo que en su esclavitud de lo real es inevitable y sugerir, mediante esforzadas técnicas, una independencia y autosuficiencia que son tan ilusas como las melodías de una ópera separadas de los instrumentos o gargantas que las interpretan" (Cartas a un joven novelista, 1997). Precisamente en esta línea se manifiesta el novelista y ensayista argentino César Aira cuando en su Diccionario de autores latinoamericanos (2001) dice lo siguiente de La ciudad y los perros: "Densa novela ambientada en el Liceo Leoncio Prado; en ella luce ya la técnica que luego el autor perfeccionaría, de una narración en varios planos simultáneos, formando un puzzle a cuyo desciframiento el lector no tarda en habituarse; pero es preciso aclarar que una vez rearmados esos elementos, la narración de Vargas Llosa es estrictamente realista”. No deja de llamar la atención que a Aira le interese tanto señalar enseguida la naturaleza realista de la novela, como si ello, el realismo, fuese más importante que el caudal de transgresiones formales que el autor inflige a la novela realista tradicional (sobre esta cuestión del realismo en la obra de MVLl volveremos más adelante). A propósito de esta novela, recordemos las palabras de José María Valverde (palabras recogidas por Ramón Medina en Diccionario Sopena de literatura (1972), que a la sazón fue miembro del jurado que le otorgó el entonces prestigioso Premio Biblioteca Breve que auspiciaba la no menos prestigiosa editorial Seix Barral (cuyo director era el poeta y me- 
morialista Carlos Barral), le dedicó a la novela ganadora: "Es la mejor novela en lengua española desde Don Segundo Sombra". Y las razones que aduce para tan (definitiva) consideración son las siguientes: "El libro de Vargas Llosa hace que, en comparación con él, la mayoría de las novelas escritas en nuestros días parezcan pobres y faltas de vigor. Pues, para resumirlo en una palabra clave, se trata de una novela 'poética' en que culmina la manera actual de entender la prosa narrativa entre los escritores hispanoamericanos. Cada palabra, cada frase, está dicha y oída en un poema. En algunas ocasiones, y precisamente para velar episodios de especial crudeza, el lenguaje se musicaliza, se pone en trance hipnótico: hasta las palabrotas se convierten en elementos rítmicos, se depuran en función de su sonido, de creación de atmósfera, confusa y sugerente a la vez, en que importa más el estado de ánimo que lo que pasa". La extensión de la cita se lo merece: son las palabras de uno de los grandes historiadores españoles de la literatura universal y de las ideas estéticas. De este veredicto de José María Valverde, me quedo con dos elementos: la poeticidad de la novela y la función de las palabras, lo que el mismo MVLl denomina en su ensayito Cartas a un joven novelista "el estilo", para alcanzar uno de los objetivos más nobles y necesarios en una novela: la persuasión. Precisamente en aquel libro MVLl nos dice, a propósito del estilo de Alejo Carpentier: "El reino de este mundo, obra maestra absoluta que he leído y releído hasta tres veces, tiene un poder contagioso y sometedor que anula mis reservas y antipatías y me deslumbra, haciéndome creer a pie juntillas todo lo que cuenta. ¿Cómo consigue algo tan formidable el estilo encorbatado y almidonado de Alejo Carpentier? Gracias a su indesmayable coherencia y a la sensación de necesidad que nos transmite, esa convicción que hace sentir a sus lectores que sólo de ese modo, con esas palabras, frases y ritmos, podía ser contada aquella historia". Exactamente lo mismo que Valverde destaca en el novelista peruano, éste destaca en Carpentier, un autor que no es de su entera simpatía.

Tal vez deberíamos detenernos un rato en el concepto de persuasión que utiliza MVLl. Veamos La ciudad y los perros. La primera interpretación que se hizo de la novela es la cruda descripción de la violencia en una institución militar. Metáfora absoluta, además, de la extendida violencia en Perú. Hasta aquí se corría el riesgo de escamotear el nivel más preciado por su autor y seguramente (como su maestro Flaubert) el más sufrido y por momentos desalentador. Además de las 
exactas palabras de José María Valverde, se sumaron en Perú las del escritor Salazar y Bondy (Ramón Medina, Diccionario Sopena de literatura): "Un cuadro viviente de nosotros mismos. El lenguaje de Vargas Llosa, sin embargo, no se deja engañar por la falacia del verismo. De rica fuerza metafórica, describe recurriendo al arsenal de la imaginación, narra superponiendo y encabalgando los planos, evoca y prevé sin trabas puristas pero también sin descuidar la eficacia literaria". La persuasión en MVLl tiene bastante que ver con el concepto, a veces maldito y denostado entre la crítica más elitista, de eficacia literaria. El verismo en toda la obra de MVL1, desde La ciudad y los perros, pasando por La guerra del fin del mundo (1981) y llegando hasta su última novela, El sueño del celta, siempre fue ajeno a su entender narrativo. La verdad humana, social y política necesita del mejor arte de ilusionismo novelesco, de su empeño persuasivo y de la utilización de la mentira literaria para representar las verdades más recónditas o disimuladas por el sistema. ¿Qué función desempeña el concepto de persuasión en la obra de MVLl? Nos contesta él mismo en Carta a un joven novelista: "Para dotar a una novela de 'poder de persuasión' es preciso contar su historia de modo que aproveche al máximo las vivencias implícitas en su anécdota y personajes y consiga transmitir al lector una ilusión de su autonomía respecto al mundo real en que se halle quien la lee. El poder de persuasión de una novela es mayor cuanto más independiente y soberana nos parece ésta, cuando todo lo que en ella acontece nos da la sensación de ocurrir en función de mecanismos internos de esa ficción y no por imposición arbitraria de una voluntad exterior. Cuando una novela nos da esa impresión de autosuficiencia, de haberse emancipado de la realidad real, de contener en sí misma todo lo que requiere para existir, ha alcanzado la máxima capacidad persuasiva". Es casi una obsesión suya esa ambición autosuficiente de la obra literaria. Esa tajante separación entre lo representado y la representación. Intentemos aclarar un poco la frase "por imposición arbitraria de una voluntad exterior". La novela tiene unas leyes propias que regulan su status de artefacto de ficción. De esto está absolutamente persuadido MVLl. No hay más que releer sus escritos fundamentales sobre el hecho literario y la relación de éste con la realidad o realidad real como él la llama. ¿Quiere decir ello que le interesa más la realidad de la ficción que la realidad real? No. Quiere decir que le interesa la ficción y el despliegue de todos sus recursos retóricos para alcanzar a vislumbrar los mecanismos humanos y sociales que 
hace que la realidad sea la que es. Es imposible creer, después de leer La fiesta del Chivo (2000), que la feroz dictadura centroamericana que describe le interese menos que la novela que la denuncia. El problema no estriba en una elección tan rupestre: ficción o realidad. MVL1 nunca dejó de apostar por la realidad exterior. Lo afirmó cuando publicó $L a$ ciudad y los perros, afirmó, por ejemplo, que de Faulkner sólo le interesaba su método de trabajo pero no su obsesión psicologista. Y acto seguido se pronuncia por su maestro de cabecera, Gustave Flaubert. ¿Y por qué el viejo maestro normando? Porque es el primero que crea los mejores instrumentos para diseccionar la realidad exterior, según afirma él mismo (1973, p. 749). Es evidente que MVLl cuando habla de "los mejores instrumentos" se está refiriendo al aparato retórico, al conjunto de reglas que exige la representación, a los conceptos narratológicos imprescindibles para plasmar aquella realidad exterior. Ese apego a la maquinaria de ilusionismo no nos indica a un escritor sólo proclive al cuidado de que dicha máquina esté siempre bien engrasada. Eso nos indica que si la tramoya novelesca funciona sin chirridos preocupantes, la realidad a la que se debe el novelista (y nunca mejor dicho, dado que Mario Vargas Llosa nunca renegó de su condición de escritor realista) tiene garantizada en la novela como representación su exigencia de verisimilitud. Y su exigencia de verdad humana. Me gustaría hacer aquí un pequeño inciso sobre el mencionado arte de la tramoya novelística. En Carta a un joven novelista, entre los dispositivos que el autor peruano desgrana para hacer creíble una historia, el tiempo es uno de ellos. Cita La máquina del tiempo, de George Wells, Rayuela, de Julio Cortázar, El tambor de hojalata, de Günter Grass, Tristam Shandy, de Laurence Sterne: todos ejemplos meridianos de juego con la noción de tiempo: tiempo interior o subjetivo y tiempo aristotélico, saltos cronológicos, simultaneidad o inversión temporal. Son, además, recursos (trucos les llama a veces nuestro escritor) utilizados recurrentemente en toda su obra. Incluso no habría más que observar el tiempo alterno de una historia que se convierte en dos en su última novela, El sueño del celta (2010). Para que el lector se haga una idea más aproximada de lo que digo, no estaría de más recordar la estructura temporal de una obra teatral del dramaturgo inglés J. B. Priestley titulada Time and the Conway (1942) (obra que en castellano se ha traducido como La herida del tiempo, una traducción dicho sea de paso que dado el asunto tratado en la obra no está nada alejada del sentimiento de tristeza e impotencia 
que destila). Priestley invierte el orden del tiempo lineal. La obra comienza por el final y termina donde todos sus personajes están llenos de esperanzas e ilusiones. Como sabemos por el principio cuál ha sido el destino de algunos de dichos personajes (muertos o frustrados de la vida) el final no puede ser más desolador. En Carta a un joven novelista no se cita este ejemplo, pero los otros que cita MVLl igualmente nos trasmiten la función que juegan los dispositivos de encantamiento de la ficción. Nos acercan mediante un recurso de la mentira novelesca a la verdad del drama (o la comedia) de la condición humana. En alguna ocasión, MVL1 ha hecho suya una máxima de su mentor supremo, Flaubert: "Escribir es una manera de vivir". Sólo para alguien que domina en profundidad el arte de la novela, dueño de una filosofía de la composición, dominador absoluto en el no menor arte de esconder una información para acrecentar el clímax del relato, maestro de la elipsis, sólo alguien hipotecado en semejante responsabilidad imaginativa puede considerar que su vida pasa esencialmente por la escritura (y luego, según el mismo reconoce, por la lectura, que es otra variante del mismo arte del novelista). Simulación, invento, alquimia, prestidigitación, trampa. Con estas palabras, MVL1 adjetiva la proeza literaria de Tirant lo Blanc, la novela de caballería, escrita en catalán, más importante del género. "Joanot Martorell los tenía en abundancia", se refiere "al talento y brujería" del valenciano. Se suele afirmar con harta frecuencia que Conversación en La Catedral no es una novela histórica. Se tiene que hacer hincapié en esta circunstancia sólo porque el hecho de que la novela abarque y aluda a la dictadura del general Manuel A. Odría y junto a ello se describa con minuciosa precisión la decadencia moral y la sensación de frustración que ese régimen genera en la colectividad, podría llegar a confundir al lector y hacerle creer que está ante un fresco histórico. ¿Qué hace que dicha obra no sea en verdad histórica? Precisamente el talento y la brujería de su autor. La condensación de diferentes tiempos en una misma oración; capítulos fragmentados que van rotando; combinación de voces narrativas en primera y tercera persona y diálogos que aparecen incrustados en otros diálogos; y, por fin, constantes saltos de tiempo y espacio. Se ha dicho no pocas veces que este método de composición a veces suele resultar mecánico e incluso no falta quien se pregunta si la narración justifica el uso de semejante arsenal tramoyístico. A mí ahora no me interesa tanto juzgar la bondad o no de estos artilugios. Me interesa lo que interesa al propio Vargas Llosa: que fun- 
cionen con la eficacia de una realidad paralela, con sus leyes propias y su poder de convicción novelesca. Abundando en este territorio, el territorio de los espejismos, me gustaría citar un reciente ensayo del director de la Real Academia Española Víctor García de la Concha: Cinco novelas en clave simbólica (2010); uno de los textos está dedicado al estudio de La casa verde, exigente análisis de su estructura simbólica. El académico en un momento de su exposición escribe: "Apunta ahí un guiño de gran interés para la construcción del relato". Y acto seguido cita un extenso párrafo de Carta a un joven novelista en el cual se describe la elasticidad en el uso del tiempo y el espacio que hace el autor a efectos de obtener el mayor grado de ilusión novelesca. Lo que conviene destacar sobre todo lo dicho respecto a la ingeniería narrativa que pone en funcionamiento MVLl no es tanto que la utilice con todas las benefactoras consecuencias para su obra, sino sustancialmente que sea absolutamente consciente de este hecho. No hay ningún novelista, sea regular, malo o excelente que no active algún dispositivo retórico en aras de hacer convincente (o persuasivo, que diría MVLl) su novela o relato, pero eso es una cosa y otra muy distinta pertenecer al selecto elenco de los escasos autores que teorizan sobre ello, los que son conscientes del peso fundamental de la tramoya en su obra y en la de los otros novelistas que leen y estudian. Tendríamos que citar a autores como Ernesto Sábato, Carlos Fuentes, los más actuales Ricardo Piglia, César Aira o el desaparecido Juan José Saer o el grupo de nuevos narradores aglutinados bajo el epígrafe de "Crack" en México. En España tendríamos que citar a Juan Benet, Juan Goytisolo y los actuales narradores jóvenes aglutinados bajo el nombre de "mutantes", como Agustín Fernández Mallo, José Francisco Ferré o Manuel Vilas. En el campo de la narrativa anglosajona tendríamos que remontarnos hasta los célebres trabajos sobre el punto de vista en la novela de Henry James, las reflexiones sobre la estructura narrativa y la conceptualización de la trama en un texto clásico como es Aspectos de la novela de E. M. Forster, Diez grandes novelas y sus autores de William Somerset Maugham (un exhaustivo y pormenorizado análisis comenzando por Tom Jones a Guerra y paz). Tampoco en tiempos más actuales son ajenos a los fundamentos de su oficio escritores de la talla de Vladimir Nabokov y sus clases sobre literatura europea, sobre los clásicos rusos e incluso un texto bastante discutible sobre El Quijote, Philip Roth, E. L. Doctorow o el premio Nobel J. M. Coetzee. 
De la competencia narratológica, la única competencia que puede llevar a la excelencia y a una verdadera autoconciencia narrativa, hallamos en MVLl pruebas irrefutables en los ensayos claves que escribió para entender los presupuestos narratológicos de autores u obras claves de la literatura decimonónica y contemporánea. Me refiero a García Márquez, historia de un deicidio (1971), La orgía perpetua (Flaubert y Madame Bovary), Carta de batalla por Tirant lo Blanc, Carta a un joven novelista, La verdad de las mentiras (2002), La tentación de lo imposible (ensayo sobre Los miserables de Victor Hugo) y "Viaje a la ficción" (2009) (ensayo sobre la obra de Juan Carlos Onetti). Esta lista de trabajos se parece más al currículum de un ensayista o teórico de la novela que de un novelista propiamente dicho. Voy a citar un largo párrafo de La tentación de lo imposible, pertenece a su primer capítulo titulado "El divino estenógrafo": "El personaje principal de Los miserables no es monseñor Bienvenu, ni Jean Valjean, ni Fantine, ni Gravroche, ni Marius, ni Cosette, sino quien los cuenta y los inventa, ese narrador lenguaraz que está continuamente asomando entre sus criaturas y el lector. Presencia constante, abrumadora, a cada paso interrumpe el relato para opinar, a veces en primera persona y con un nombre que quiere hacernos creer es el del propio Victor Hugo, siempre en alta y cadenciosa voz, para interpolar reflexiones morales, asociaciones históricas, poemas, recuerdos íntimos, para criticar a la sociedad y a los hombres en sus grandes designios o en sus pequeñas miserias, para condenar a sus personajes o ensalzarlos. Con frecuencia nos asegura que él es apenas el obediente escribano de una historia anterior a la novela, cierta como la vida y verdadera como la misma verdad, que lo precede, lo anula y lo trasciende, a él, simple intermediario, mero copista de lo real. ¡Qué cuentanazo! En verdad, él es el astuto hacedor y la figura estelar de esta grandiosa mentira, fraguada de pies a cabeza por su fantasía y dotada de vida y verdad no por sus semejanzas con una realidad preexistente, sino por la fuerza de la inspiración de quien la escribe y el poder de sus palabras, por las trampas y sortilegios de su arte". Se justifica esta inserción textual. Aquí aparece resumido el concepto que tiene (mejor deberíamos decir, ante el cual se rinde) MVLl de la ficción. Meridianamente nos señala el papel invasor de Victor Hugo a través de la voz narradora en Los miserables, de la misma manera que nos convencía de la programática invisibilidad e impersonalización del autor en su estudio sobre Madame Bovary. Palabras como "trampa", "sortilegio", "mentira", nos arrastran 
al meollo de la fantasía creadora. La que al mismo MVLl fascina y la que él mismo utiliza para las mentiras de sus verdades.

Al hilo de estas consideraciones, convendría hacer un alto en el camino y detenernos en dos de sus últimas novelas, El Paraíso en la otra esquina (2003) y Travesuras de la niña mala (2006). Son también paradigmas, no menos que sus novelas más difundidas y estudiadas, en la organización y manipulación de los conceptos narratológicos. Veamos El Paraíso en la otra esquina. En su novela más inmediatamente anterior La fiesta del Chivo, MVLl ya había ensayado con meridiana eficacia la ficción-documento, un género en que hay que tener las ideas muy claras si no se quiere terminar marginando la ficción en beneficio del documento. La investigación de campo, como no podía ser de otra manera en el escritor peruano (la misma, por otra parte, que lleva a cabo en El sueño del celta, aunque sus resultados, a mi modesto entender, no se repiten con su misma excelencia artística), era exhaustiva, engrasada para aumentar el impacto emotivo de la realidad mediante un afinadísimo proceso de representación novelística. En El Paraíso en la otra esquina la mecánica de infraestructura novelística es parecida. Información detallada y extensa documentación. El asunto argumental y su nudo temático es más complejo. Veintidós capítulos se van alternando (esa propensión a la estructura binaria tan característica en varias novelas suyas) para dar vida a dos personajes míticos en dos áreas diferentes de la actividad social, política y cultural europea del siglo diecinueve. Uno es Flora Tristán, la célebre luchadora francesa por los derechos de los trabajadores y fundadora de las reivindicaciones feministas. Flora viaja por toda Francia para difundir su ideario político, moral y feminista. Muerta a los cuarenta y un años, su vida ha sido un rosario de desencuentros afectivos, tortuoso sufrimiento matrimonial y entrega a la causa de justicia social y la igualdad entre hombres y mujeres. Medio siglo más tarde, hallamos la figura de su nieto Paul Gauguin abandonando las comodidades burguesas de la Francia del Segundo Imperio, en Tahití, en medio de la cultura maorí, desafiando la incomprensión e intolerancia de los franceses colonialistas, y en a la búsqueda de su lugar pictórico, su tardía e inmortal vocación, en un sensual como imposible paraíso. El dibujo, el arte de la brujería, al servicio de estos dos seres irrepetibles sirve a MVLl para transformarlos en seres de ficción y en metáforas imborrables de cómo a veces una derrota personal concluye a la postre en una victoria histórica. Es el camino que traza la pluma 
del escritor de la estética a la ética o viceversa. La novela comienza con el relato de las peripecias divulgadoras de Flora Tristán y termina con la muerte del genial pintor en su doloroso paraíso. La enorme destreza del autor puede con todo ese material. La labor consiste, en términos generales, en manipular las dos biografías para que no quede de ellas ningún rastro historicista y sí toda la potente sensación de que nos hallamos antes dos personajes eminentemente literarios. Sabemos que son históricos, sabemos que existieron, pero la escritura embrujada de MVLl nos conduce a su literariedad más rotunda. A este cometido ayuda, probablemente, el hecho de que Flora Tristán y su insospechado nieto pintor tenían esa aura de seres de ficción, como sacados de la galería de seres imaginarios de Marcel Schwob. En términos de carpintería narrativa, MVLl solventó todos los problemas que se presentaban en su comprometida (nunca mejor dicho, dado la naturaleza reivindicativa de uno de sus personajes) empresa. Desde dos tipos de narración, una en tercera y otra en segunda persona, las vicisitudes de sus dos héroes novelescos abarcaban el último año de vida de la luchadora y los diez finales del aventurero de Tahití. Pero MVL1 logra agotar cada milímetro de existencia de ambos. Su estilizado sentido del naturalismo narrativo nos pone en presencia de momentos inolvidables en el capítulo de las descripciones más abyectas de la explotación y la injusticia humanas. A través del sufrimiento de Flora y la desgarrada tristeza de Paul, nuestro autor ilumina los costados más inhumanos del capitalismo y las lacras del colonialismo (asunto éste que vuelve a tratar en El sueño del celta), amén de la mezquindad de no pocos ilustrados, poetastros, iluminados y revolucionarios de salón. La depuradísima técnica ha obrado el milagro de la metáfora histórica.

Veamos ahora Travesuras de la niña mala. La realidad esta vez del mundo contemporáneo cede paso, como es proverbial en toda la obra de MVLl, a una ejemplarizante realidad verbal. Toda la pasión que puso MVLl por la novela decimonónica, el dibujo irónico-naturalista, el esbozo distanciado del melodrama, sumado a su pasión histórica y la trascendencia moral, ingredientes que vimos en su máxima expresión en El Paraíso en la otra esquina, si asumimos todos estos logros podremos ver con mayor claridad la hechura de la heroína en Travesuras de la niña mala. Evidentemente no tiene la dimensión documental de la anterior. Ni su estructura contrapuntística. Pero como aquella, explota al máximo su carpintería para la construcción de uno de los caracteres más 
inolvidables de todos los que ha creado MVL1. La novela está narrada en primera persona. Sus escenarios son Lima, París, Londres y Madrid. Esto nos pone en la siguiente tesitura. MVLl juega con lo autobiográfico (como lo hizo, según él mismo lo reconoció en varias ocasiones, en La ciudad y los perros). Todo el mundo sabe de su estada en París. También Londres. El que narra, Ricardo Somocurcio, podría responder como lo hizo el mismo Flaubert: "La chilenita soy yo" (en referencia a Otilia, la protagonista de la novela). ¿No había afirmado en La orgía perpetua nuestro autor que sólo se puede inventar a partir de historias personales? Esto por un lado. Por otro, y sin dejar su ensayo sobre Flaubert, en Travesuras de la niña mala convergen cuatro conceptos que MVLl subraya como capitales del novelista normando: violencia, rebeldía, sexo y melodrama. Siete capítulos componen la novela. Otilia y sus múltiples máscaras son la columna vertebral de la historia. A su vez cada capítulo es una historia de destinos y azares que van jalonando el relato de Ricardo. Y que le van larvando en su subconsciente la novela que estamos leyendo. Todo comienza en el barrio elegante y pituco de Miraflores. Allí comienzan las andanzas de la chilenita. Luego viene el viaje a París del narrador, Ricardo. Y el encuentro casual con la chilenita, que ahora se llama (aunque ya se había develado que la heroína no era menos peruana que los peruanos de la alta burguesía que quería emular) Madame Arnoux (por cierto, una inequívoca alusión a la Madame Arnoux de La educación sentimental de Flaubert). Ricardo inicia una tórrida relación amorosa entre clandestina y espaciada por los incontables abandonos de la chilenita, o la niña mala del título de la novela. Para Ricardo, la pequeña y agraciada mujer de sus días es como una maldición necesaria. Una enfermedad que no se debe curar a condición de que nos pague con una felicidad tan inconstante y dolorosa como luminosa. Travesuras de la niña mala nos relata una historia de amor. Sólo el refinado oficio en el manejo de los hilos narratológicos de su autor, hace que esta historia predominante en el conjunto de la novela adquiera su premeditado condimento melodramático. Habría que remontarse hasta La tía Julia y el escribidor (1977) para encontrar una historia concebida con su misma madera: romance encendido, melodrama y una suerte de pastiche de costumbrismo. Es verdad que la novela introduce ingredientes políticos e históricos (que bien podrían leerse en clave rabiosamente contemporánea). Y sumado a ello no debe soslayarse un cierto aire de desilusión generacional, a la manera en que Balzac 
y Flaubert abordaron este tema. Pero así y todo me quedo con una sensación sobredeterminante: la de estar asistiendo a la "mise en scene" de una heroína operística. El autor peruano insufla a su figura central esa naturaleza decimonónica de heroína arribista. La ambición de la niña mala, su necesidad de ascenso social se va fraguando con la hechura de una personalidad de magnética psicología. Sus patológicas relaciones con algunos hombres, sus claudicaciones éticas, no esconden ante Ricardo su afán de redención mediante el ambiguo y casi indescifrable amor que le profesa. Para que no quede duda alguna sobre la estirpe psicológica (y sociológica) a la que pertenece la niña mala, en un momento dado MVLl hace visionar a Ricardo La diligencia, el célebre film de John Ford. Cuenta nuestro autor que el lector recuerde que esa película se basó en el relato de Guy de Maupassant "Bola de sebo". La heroína de esa pieza maestra de la literatura breve despierta en sus congéneres un calculado desprecio, igual que la heroína de nuestra novela. Es un guiño intertextual, un homenaje que nos recuerda a otro de similar calibre: en el cuento de Jorge Luis Borges, "La espera", su protagonista está visionando una película basada en el relato de Hemingway Los asesinos, como si en esa cinta estuviese dibujado su propio desdichado destino. En estas dos novelas se complementan diferentes técnicas de representación. La voluntad de historicidad, la configuración de los papeles individuales y colectivos y su a veces dramática dialéctica, lo cómico y lo trágico en un dilema sentimental de nuestros días, todo ello es el resultado de un profundo conocimiento de los resortes internos de la ficción y de su lúcida aplicación. No creo que haya que insistir que no todas las novelas de MVLl alcanzan pareja excelencia estética. Hay en su extensa bibliografía textos que bien pudo evitarse, sobre todo si se comparan con las altas cotas que alcanza en otros. Pero todos ellos tienen siempre la convicción prioritaria de la arquitectura narrativa. Me viene a la memoria un párrafo dedicado a una novela de la también premio Nobel Doris Lessing; se trata de una consideración sobre El cuaderno dorado en un artículo integrado en La verdad de las mentiras: "Se trata de una pequeña vuelta de tuerca, que deja flotando en el ánimo del lector una ambigüedad más en un libro repleto de enigmas. Pero es importante subrayar este barroquismo de la estructura para mostrar cómo, en esta novela 'comprometida', hay en la forma una riqueza de inventiva que va a la par con la complejidad de su contenido". Redundando en mi tesis, puedo aportar otro ejemplo bastante elocuente. Se 
trata de otra consideración sobre el estilo y la estructura de El corazón de las tinieblas, de Joseph Conrad, también recogido en La verdad de las mentiras. El texto "Las raíces de lo humano" fue escrito en 2001, es decir, nueve años antes de publicar El sueño del celta (menciono esto, teniendo en cuenta que en dicho texto se hace hincapié explícito en la furia colonizadora y exterminadora del rey de Bélgica Leopoldo II, asunto crucial en la novela que el escritor peruano dedicó al líder independentista irlandés). Escribe MVLl: "La extremada complejidad de la historia está muy bien subrayada por la compleja estructura de la narración, por los narradores, escenarios y tiempos superpuestos que se van alternando en el relato. Vasos comunicantes y cajas chinas se relevan e imbrican para edificar un todo narrativo funcional y sutil". En el mismo texto, hace más tarde referencia a la estructura binaria del relato y a la convivencia de voces narradoras encajadas una dentro de otra, y nuestro autor se permite disentir de una interpretación del crítico inglés F. R. Leavis: "Deploro en este estilo, la insistencia adjetivadora (adjectival insistente), algo que a mi juicio, es más bien uno de sus atributos imprescindibles para desracionalizar y diluir la historia en un clima de total ambigüedad, en un ritmo y fluencia de realidad onírica que la hagan persuasiva. Esta atmósfera reproduce el estado anímico de Marlon, a quien lo que ve, en su viaje africano, en los puestos y factorías de la Compañía, deja perplejo, confuso, horrorizado, en un crescendo del exceso absoluto que la narración alcanza con él. Relatada en un estilo más sobrio y circunspecto, aquella desmesurada historia sería increíble". No creo que haya que subrayar el placer que le depara a MVLl desmontar el mecanismo de relojería del célebre relato de Conrad. En justicia habría que agregar que en El sueño del celta, donde los ojos de algunos de sus personajes han tenido que ver lo mismo que vieron los horrorizados ojos de Kurtz, no alcanza la exigencia estética que logra Conrad en su demoledora metáfora.

Dos consideraciones más: siempre me ha admirado el celo crítico de MVLl. No tanto para juzgar, que a veces sí lo hace aunque nunca de manera granítica, como para destripar todo organismo narrativo que se ponga a tiro de su interés. Y su ojo clínico para captar situaciones llevadas casi a la categoría de conceptos narratológicos. Como ejemplo de ello me remito a tres aspectos de la representación novelística según MVLl: el primero hace referencia a lo que él llama en su ensayo sobre Madame Bovary las acciones de multitud; dice allí: "Otro aspecto de la novela no ha perdido su vigor: el épico, las acciones de multitud, que 
ningún otro novelista, salvo Tolstoi, ha sabido realizar con tanta eficacia como Flaubert". Y cita la famosa escena de los comicios agrícolas. Le fascina "la alternancia de lo colectivo y lo individual", de "lo general y lo particular", atribuye a la maestría del normando el murmullo que se pega a nuestros oídos de las voces que invaden la plaza del pueblo, el murmullo de la multitud. El segundo aspecto lo encontramos en La tentación de lo imposible: aquí MVL1 lo llama el "personaje colectivo": su función es la de dotar a la novela, en este caso se trata de Los miserables, de cierta pluralidad: son masas de personajes vinculados por parecidos esquemas psicológicos y sociales que hablan todos como si fueran un solo ser social y psicológico. Y queda por fin el tercer aspecto, que nuestro autor llama en su ensayo sobre el Tirant lo Blanc "Los cráteres activos": "Son aquellos puntos de una novela donde se registra una fuerte concentración de vivencias. Focos ígneos, derraman un flujo de energía hacia los episodios futuros y anteriores, impregnándolos de vitalidad cuando no la tienen, entonándolos cuando sus vivencias son débiles. Ninguna novela mantiene una misma sostenida vivencia de principio a fin: su grandeza consiste en la existencia de un mayor número de 'cráteres activos' en el espacio narrativo, o si no, en la intensidad de sus núcleos de energía”.

\section{Algunas palabras sobre el realismo en Vargas Llosa}

Mario Vargas Llosa nunca negó la naturaleza realista de su literatura. Incluso nunca negó el proceso de transfiguración de experiencias personales en materia de invención. En los años setenta se distanció y criticó el llamado realismo social por el carácter sectario y totalitario de sus fundamentos ideológicos. En todo caso siempre fue consciente de que su realismo, tan cercano al "realismo irónico" de naturaleza cervantina, podía sufrir la tensión de equidistar entre su debida servidumbre a las realidades sociales y el firme propósito de defender el principio de autonomía de la obra literaria. Una tensión, en suma, entre el principio de realidad y el principio de ficcionalización. Hay teóricos, como Darío Villanueva ("Fenomenología y pragmática del realismo literario", 1991), que sostienen la necesidad de encontrar un punto de equilibrio entre la autonomía de la obra literaria y su condición de institución social. Villanueva describe dos campos conceptuales básicos en el realismo: realismo genético, para el cual la realidad es anterior a todo proceso 
de transfiguración; el realismo formal o inmanente como antagónico al anterior y, sobre todo (y aquí Villanueva recurre a Guy de Maupassant), como ilusión verista. De los dos, es evidente que la narrativa de MVLl pertenece al realismo formal, el que privilegia la literariedad, la realidad real pasa a ser realidad textual. De los tres grandes novelistas franceses del siglo diecinueve, Stendhal, Balzac y Flaubert, MVLl siempre ha tomado como modelo al tercero. En un texto clásico sobre la cristalización de la realidad en la obra literaria, Mimesis: La realidad en la literatura, de Erich Auerbach, se trata el método de representación de Flaubert a la hora de construir su heroína: Emma Bovary. Auerbach afirma que nunca Emma nos inspira absolutamente un sentimiento trágico de su existencia, aun cuando es bastante trágica. Sólo el uso del estilo de Flaubert hace que la vida sin horizonte de su protagonista, lo "caótico de su vida" como dice el mismo estudioso alemán, se nos imponga como un sentimiento ambiguo de extrañamiento: ni risa, ni lástima, aunque haya razones para ello. La descripción pura de un drama provinciano que no nos inspira emoción alguna. Y sin embargo en la novela de Flaubert no están ausentes ni la gravedad, ni el peso insoportable de una existencia a la deriva. Como tampoco están ausentes la tragicidad y la comicidad. Con estos elementos se nutre la escritura de MVL1. Como las calculadas comicidad, ironía y sátira en Pantaleón y las visitadoras (1973) o La tía Julia y el escribidor. O la controlada comicidad en Las travesuras de la niña mala.

Asociada al concepto de realismo, independientemente de lo sofisticadas que sean las técnicas de representación de MVLl, lo cierto es que siempre se impone en su obra la voluntad de narratividad. ¿Por qué hago esta afirmación que puede parecer innecesaria? Precisamente en un reciente trabajo a camino entre la ficción y la crítica literaria, Chet Baker piensa en su arte, el escritor barcelonés Enrique Vila-Matas urde un dilema teórico que se resume en lo siguiente: según el narrador de la "crítica-ficción", así le llama, su corazón está dividido entre "el hilo Finnegans" (por Finnegans Wake, de James Joyce) y "el hilo Hire" (por la novela de Georges Simenon La prometida de monsieur Hire). Uno representaría el texto como conflicto con la linealidad, como erosión del concepto cartesiano de novela y el otro sería el confort burgués, la felicidad absoluta ante el relato que no "soporta el desorden atolondrado de la vida". En la literatura de MVL1 las cosas no se dan de esta manera tan taxativa. Es evidente que en novelas como Conversación en $\mathrm{LaCa}$ 
tedral, la dialéctica entre lo singular de las vivencias de sus personajes y el destino colectivo, se puede interpretar como un ajuste de cuentas con la propia historia del Perú, pero al margen de su horizonte éticopolítico, así y todo no puede negarse que la novela acusa un grado de narratividad tan genuina como la que pudo emplear años más tarde y en una tesitura narrativa muy distinta en La guerra del fin del mundo.

\section{EPílogo}

Nadie puede ser un buen novelista si antes no es un buen lector. Por buen lector entiendo un buen analista de lo que lee. Un intérprete de la ficción que por un momento lo aparta de la realidad pero lo introduce en otra paralela. Mario Vargas Llosa fue y sigue siendo un buen lector. Analizó, buceó en distintas tradiciones. Interpretó y usó la que más se aproximaba a sus necesidades literarias, a su pasión por la ficción. En su discurso ante la Academia Sueca titulado "Elogio de la Lectura y la Ficción" (2010), quedan resumidas esas dos grandes pasiones. Con ellas transfiguró distintas realidades, cercanas y lejanas en el tiempo y el espacio. Dice en dicho discurso: "Aunque me cuesta mucho trabajo y me hace sudar la gota gorda, y como escritor, siento a veces la amenaza de la parálisis, de la sequía de la imaginación, nada me ha hecho gozar en la vida tanto como pasarme los meses y los años construyendo una historia, desde su incierto despuntar, esa imagen que la memoria almacenó de alguna experiencia vivida, que se volvió un desasosiego, un entusiasmo, un fantaseo que germinó luego en un proyecto y en la decisión de intentar convertir esa niebla agitada de fantasma en una historia. 'Escribir es una manera de vivir', dijo Flaubert [...] Llegar a sentir el vértigo al que nos conduce una novela en gestación, cuando toma forma y parece empezar a vivir por cuenta propia".

En el prólogo a Diez grandes novelas y sus autores, Somerset Maugham dice: "Al final todo se resume en la cuestión de si la novela es una forma de arte o no lo es. ¿Es su finalidad instruir o deleitar? Si es instruir, no es una forma de arte. La finalidad del escritor de obras de ficción no es instruir, sino deleitar". Si no somos demasiados hipócritas, reconozcamos que leyendo a Mario Vargas Llosa sentimos deleite. No todas sus novelas nos deleitan por igual. Pero por sobre todas las cosas sentimos el empeño del mago. El triunfo de la invención y el incurable vértigo de la forma que lo consume. 


\section{OBRAS CITADAS}

Aira, César. Diccionario de autores latinoamericanos. Buenos Aires: Emecé/Ada Korn Editora, 2001.

Auerbach, Erich. Mimesis: La representación de la realidad en la literatura occidental. México: FCE, 1983.

García de la Concha, Víctor. Cinco novelas en clave simbólica. Alfaguara, 2010.

Maugham, Somerset. Diez grandes novelas y sus autores. Tusquets Editores, 2004.

Medina, Ramón y otros. Parnaso Diccionario Sopena de literatura. S.A. Editorial Ramón Sopena, 1972.

Vargas Llosa, Mario. La ciudad y los perros. Barcelona: Seix Barral, 1963.

- Declaraciones recogidas por Ramón Medina en Diccionario Sopena de literatura. Barcelona: Editorial Ramón Sopena, 1972.

- La orgía perpetua: Flaubert y Madame Bovary. Taurus, 1975.

- Carta de batalla por Tirant lo Blanc [1969]. Seix Barral, 1991.

Cartas a un joven novelista. Ariel, Planeta, 1997.

La tentación de lo imposible. Alfaguara, 2004.

"Las raíces de lo humano" [2001]. En Mario Vargas Llosa, La verdad de las mentiras. Madrid: Punto de Lectura, 2007.

“Elogio de la lectura y la ficción". Estudios Públicos, 120 (2010).

Vila Matas, Enrique. Chet Baker piensa en su arte. DeBolsillo, 2011.

Villanueva, Darío. "Fenomenología y pragmática del realismo literario" [1991].

En Darío Villanueva, Teorías del Realismo Literario. Madrid: Instituto de España. Espasa Calpe, 1992. 